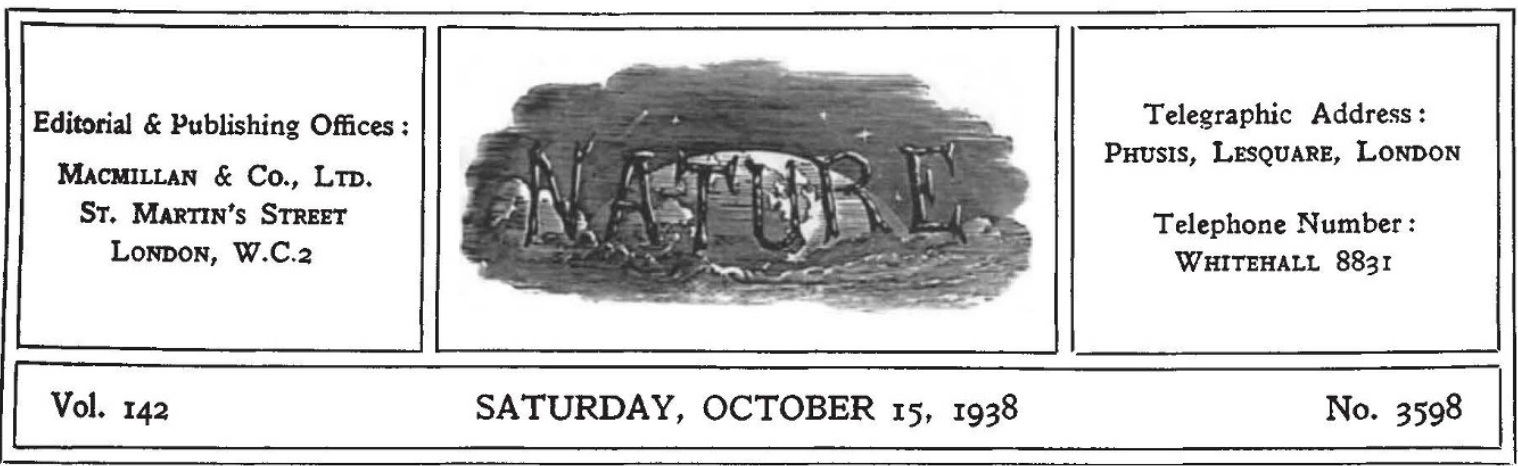

\title{
Science and National Service
}

$\mathrm{I}^{\mathrm{T}}$ was apparent during the recent critical weeks that, though the problem of the utilization of science in war-time had been under consideration, no comprehensive scheme for this purpose was in existence. The immediate danger is now past, but there are clear signs that the peace obtained by consultation is not of a character which will permit of any relaxation of military preparations. The problem thus still remains an urgent one, though we may hope for the time to work out a reasonable rather than improvised scheme. If this is to be done in a way that is not likely to waste the capacities of scientific workers, or to damage the structure of scientific knowledge and research, scientific men will need to take the matter in hand.

In the first place, it must be emphasized that no scheme for the utilization of science can be satisfactory to citizens and men of science unless its ultimate aim-the utilization of science for human welfare in times of peace-is kept steadily in view. The idea which appears to be prevalent in certain countries, that the main activity of human communities is the waging of war and that peace is merely an armistice for future war preparations, is not one which is compatible with the maintenance of civilization or of science. Consequently, the organization of scientific workers for war must be conceived in such a way that the minimum damage is done to the possible beneficial utilization of science. This involves the safeguarding of fundamental scientific research and of the main lines of its application, so that once the danger of war is definitely removed, science can advance as rapidly as possible in carrying out its true purpose. It involves, further, the protection of the life and efficiency of a sufficient number of key scientific workers, and the maintenance of a continuity of scientific teaching and training. It would be found that such provision would not, in fact, be detrimental from the strictly military point of view, and that the effective utilization of science for war purposes requires, to be fully effective, a proper balance between civil and military uses for science, even in war-time.

If we are to face in a realistic way the possibility of war, certain steps should be taken immediately in the organization and the use of science, while others of more drastic character will be needed only if and when war breaks out. Scientific war preparations in peace-time involve two types of activity. The first is the organization and development of basic and applied scientific research in such a way that it may be of value for war without losing its actual or potential peacetime value. The second is the training of a certain number of scientific men, and the preparation of many more, for possible war-time activities.

It is clear that measures that were adequate for the Great War are unlikely to prove so in a future war waged under conditions which will probably be even more severe and prolonged. Preparation for such a war requires not only a much more thorough organization of science, but also a much closer integration between scientific research and the other activities of the community, particularly those of industrial production, agriculture and health.

When we review the potential needs of the British Isles, or the British Commonwealth, in war-time, we see that they are primarily those of maintaining a human community at full effectiveness under conditions of shortage of supplies, shortage of men and of general disorganization due to enemy attack. Most of these are simply the problems of normal civilized life raised to a 
much higher degree of urgency; consequently, development of scientific research to cope with these problems is bound to follow in the main the same lines as those required for the proper utilization of science in peace.

The five principal needs of a modern community under war conditions are : (1) maintenance of the military and civil populations; (2) maintenance of war production; (3) defence against aerial attack ; (4) the carrying on of military, naval and air operations ; (5) care of casualties. Each of these problems makes special demands on certain of the sciences, and requires peace-time development of research on certain specific points. The strain of war conditions is not uniformly felt; it bears particularly hard on certain sectors in which there are deficiencies not perceptible in peace-time. These weak points are those most likely to break, and the breaking of any one of them may entail military defeat, or, what is more likely under modern conditions, economic collapse.

It is impossible to itemize all these weak places, but there are at least six which are of cardinal importance: food, non-ferrous metals, rubber, motor-fuel, optical instruments and medical supplies. For all of these we are dependent to a large degree on imports which may be restricted or cut off altogether. At the same time, they are all products in which an application of science can provide either alternative sources or effective sub. stitutes. If this is to be done, however, it is not only necessary to provide, as at present, for applied research in these fields : fundamental research is just as necessary, provided it is well linked with practice. In the case of food, for example, the work of geneticists, plant physiologists, biochemists and nutrition experts is no less important than that of agriculturists.

Similar considerations apply to the more purely military aspects of war. The defence of the civil population against aerial attack has created entirely new problems. Protection against the effects of high explosives will necessitate a combination of evacuation and construction of shelters, which will involve research in population distribution and in building

The carrying on of military operations is itself a large-scale industrial undertaking. The question of fuel may be a crucial one. Already a great deal of fundamental and applied research has been done on the problem of artificial fuels, but it is still open to doubt whether a more direct attack on the problem, free from the confusion of rival interests, might not yield more economical production of motor-fuel from coal, than at present obtains. Another characteristic of modern warfare is the dependence it places on scientific means of detection and communication. An adequate supply of optical instruments of the highest precision is needed, and this requires a development of the optical industry and of optical research on a scale that has not yet been attempted.

With the new weapons of destruction which have been developed since the last war, and particularly with the bombing of cities, casualties are likely to be heavy and serious. The medical profession will have to face a heavier task than in any previous war. It is difficult to improve technique in dealing with casualties under war conditions, and therefore special efforts in medical research are required in order to prepare new and improved methods of treatment and rehabilitation. Much greater quantities of medical supplies will be required, particularly of drugs, for there is reason to believe that the home production is inadequate even for peace-time. We need at once to develop drug production and research on drugs comparable to that already existing in Germany, and on a far larger scale than the $£ 30,000$ provided by the Medical Research Council for chemotherapy allows.

These are some of the more obvious needs that war would bring for applied and fundamental science. There are many others which will be apparent to those working in different fields. But if these needs at least are not dealt with now, by provision and adequate facilities for research on both laboratory and factory scale, the effect of this neglect in war-time will be disastrous. Further, it will be necessary to secure that men trained in the different scientific techniques are reserved for scientific service in war-time, and that the best use is made of the registers now being compiled by the universities, possibly through the collaboration of the learned societies.

The problems which war raises for scientific research are, however, not independent, and demands made for one or another of them would, in the absence of co-ordination, merely increase the existing confusion and inefficiency of research. If science is to be used to some extent for the protection of humanity in war, it needs to be organized more comprehensively than it is at present. This is not to criticize the existing organization of science, but to point out that it requires to be extended and more closely knit. We need a National Research Council covering the whole of 
science and relating it to the running of the community both in peace and in war. The French Government has just set up such a council, which is linked with all the defence Ministries as well as with that of national education. This is not the place to discuss precisely how such a council should be formed or how it would group existing organizations, but certain requirements must be satisfied if it is to succeed in its main purpose of utilizing science for national service. In the first place, it will need to command the active loyalty of a great majority of the scientific workers in Great Britain. They will best collaborate with a body which they feel represents the most effective scientific workers, and not simply those chosen on a basis of seniority or official position. Further, at any rate the younger among them, will not work wholeheartedly, if at all, to organize science for a possible war unless they see evidence that the intention of political policy in general is to prevent war. Lastly, if the war should come, their attitude towards it will largely depend on whether it is a war for or against the principles of democracy and civilization.

There are two ways in which the scientific man can be used, under war conditions. One is by putting him in the position of a military subordinate, whose business is to obey orders and not to think. The other is to give him a chance to use his imagination and knowledge co-ordinated with that of his fellow scientific workers and technicians, to criticize and direct, in so far as he is competent, the character of operations. In the first way it is impossible to get the best out of scientific men, even if they are willing to comply with the conditions. Any adequate organization of science cannot relinquish the fundamental scientific right of criticism. Stifling of criticism led to great losses in 1914-18; it might have an even more disastrous result in a future war. The full utilization of scientific workers requires the use of their ingenuity far more than of their routine service, and this can only be secured by giving them opportunities and liberty of initiative. The degree to which this is done may be a decisive factor; and its neglect might mean defeat in which the prospects of reconstruction afterwards would be irretrievably damaged. It is for the citizens and scientific men in the democratic States to see that this does not happen on their side.

\section{Foundations of Human Inequality}

\section{The Origin of the Inequality of the Social Classes}

By Prof. Gunnar Landtman. Pp. xvi + 444. (London : Kegan Paul and Co., Ltd., 1938.) 21s. net.

PROF. LANDTMAN'S book, in spite of certain shortcomings, will obtain a permanent place in anthropological literature as an encyclopædia of fact and theory, on such subjects as the earliest differentiation of society according to age, sex and personality; the role of wealth, manual skill and commercial efficiency in creating primitive stratification; the question of early phases of priesthood, in its dogmatic, social and ritual aspects. The chapters on slavery are valuable as a summary of older work, supplemented by recent evidence. The book deals somewhat briefly in the last two divisions with the genesis of nobility and with the origins of government.

Inspired though it is by the classical tradition of British anthropology, the book lacks the charm and the intuitive genius of Frazer; it falls short of the standard set by Westermarck in his almost uncanny creative acumen in the analysis of fact and its relevance; it has not the flashes of inspiration characteristic of the work of Crawley. At the same time, the sincerity, the thoroughness and the complete impartiality in dealing with facts and theories will allow the reader to draw his own conclusions from the material, conscientiously and skilfully accumulated by the author.

The very quality of the book and its high standard of scholarship invite criticism on one or two points. In his treatment of the origins of government, for example, the author fails in my opinion to recognize some of the relevant aspects of the problem. It is, of course, necessary to discuss whether in certain primitive communities power is vested in a council or a monarch, in a male chief or a queen-mother, handed down by a hierarchy or distributed through a confederacy. Another important question, however, still remains: In what way do the rulers of primitive peoples carry out their work? And, indeed, in what does this work consist? Do they ever take any legislative initiative, or is custom regarded as unalterable? In what way are their administrative functions carried out-through specific executive 